\title{
The Cooperation of Sustained and Phasic Inhibitions Increases the Contrast of ITD-Tuning in Low-Frequency Neurons of the Chick Nucleus Laminaris
}

\author{
Rei Yamada, ${ }^{1,2}$ Hiroko Okuda, ${ }^{2}$ Hiroshi Kuba, ${ }^{1,2,3}$ Eri Nishino, ${ }^{2}$ Takahiro M. Ishii, ${ }^{2}$ and Harunori Ohmori ${ }^{2}$ \\ ${ }^{1}$ Department of Cell Physiology, Nagoya University Graduate School of Medicine, Nagoya 466-8550, Japan, ${ }^{2}$ Department of Physiology and Neurobiology, \\ Faculty of Medicine, Kyoto University, Kyoto 606-8501, Japan, and 3JST PRESTO, Saitama 332-0012, Japan
}

\begin{abstract}
Neurons in the nucleus laminaris (NL) of birds detect the coincidence of binaural excitatory inputs from the nucleus magnocellularis (NM) on both sides and process the interaural time differences (ITDs) for sound localization. Sustained inhibition from the superior olivary nucleus is known to control the gain of coincidence detection, which allows the sensitivity of NL neurons to ITD tolerate strongintensity sound. Here, we found a phasic inhibition in chicken brain slices that follows the ipsilateral NM inputs after a short time delay, sharpens coincidence detection, and may enhance ITD sensitivity in low-frequency NL neurons. GABA-positive small neurons are distributed in and near the NL. These neurons generate IPSCs in NL neurons when photoactivated by a caged glutamate compound, suggesting that these GABAergic neurons are interneurons that mediate phasic inhibition. These IPSCs have fast decay kinetics that is attributable to the $\alpha 1$-subunit of the $\mathrm{GABA}_{\mathrm{A}}$ receptor, the expression of which dominates in the low-frequency region of the NL. Model simulations demonstrate that phasic IPSCs narrow the time window of coincidence detection and increase the contrast of ITD-tuning during low-level, low-frequency excitatory input. Furthermore, cooperation of the phasic and sustained inhibitions effectively increases the contrast of ITD-tuning over a wide range of excitatory input levels. We propose that the complementary interaction between phasic and sustained inhibitions is the neural mechanism that regulates ITD sensitivity for low-frequency sound in the NL.
\end{abstract}

\section{Introduction}

Sensing the interaural time difference (ITD) of a sound is crucial in localizing the sound source particularly for low-frequency sounds (Rayleigh, 1907). Binaural sound signals first converge in the medial superior olivary nucleus (MSO) in mammals and in the nucleus laminaris (NL) in birds. The dendrites of bipolar neurons in these nuclei receive inputs from the bilateral cochlear nuclei (the ventral cochlear nucleus in mammals and the nucleus magnocellularis (NM) in birds). These bipolar neurons detect the coincidence of bilateral inputs and change their firing rate as a function of the ITD. However, the range of ITD that the animals experience is quite small, and the neural circuit requires specialization for processing the ITD cues.

Inhibitory synapses are proposed to increase sensitivity to ITDs in mammals and birds (Grothe, 2003; Konishi, 2003); however, the proposed role of inhibition is different between these animal species. In mammals, glycinergic feedforward inhibition through the medial nucleus of the trapezoid body is hypothesized

\footnotetext{
Received May 16, 2012; revised Jan. 10, 2013; accepted Jan. 15, 2013.

Author contributions: R.Y., H.K., T.M.I., and H. Ohmori designed research; R.Y., H. Okuda, E.N., and T.M.I. performed research; R.Y. analyzed data; R.Y., H.K., and H. Ohmori wrote the paper.

This work was supported by a Ministry of Education, Science, and Technology Grant-in-aid (21700431, R.Y.; 22680031, H.K.; and 20220008, H. Ohmori) and JST PRESTO program (H.K.). We thank Professor L.0. Trussell for critically reading this manuscript.

Correspondence should be addressed to Rei Yamada, Department of Cell Physiology, Nagoya University Graduate School of Medicine, 65 Tsurumai-cho, Showa-ku, Nagoya 466-8550, Japan. E-mail: yamada@med.nagoya-u.ac.jp. DOI:10.1523/JNEUROSCI.2377-12.2013

Copyright $\odot 2013$ the authors $\quad 0270-6474 / 13 / 333927-12 \$ 15.00 / 0$
}

to create an internal delay to compensate for the ITD in the MSO rather than the hard-wired delay-line mechanism proposed in the NL in birds (Brand et al., 2002; Grothe, 2003; Pecka et al., 2008; but see Joris and Yin, 2007). In birds, the NL receives GABAergic inhibitory projections from the superior olivary nucleus (SON). The SON is triggered by inputs from the nucleus angularis (NA), which senses sound intensity (Lachica et al., 1994; Yang et al., 1999; Burger et al., 2005). This sound-intensitydependent inhibition is proposed to have sustained effects in NL (Lachica et al., 1994; Yang et al., 1999) and control the gain of the coincidence detector neurons. This inhibition confers tolerance to loud sounds in the detection of ITDs in the NL (Peña et al., 1996; Dasika et al., 2005). Although the tonotopic organization of the SON is less precise than the organization found in the excitatory nuclei (Fukui et al., 2010; Tabor et al., 2012), the projection from the SON is still frequency-region dependent and is extensive to the low characteristic frequency (low-CF) region of the NL (Nishino et al., 2008). Consequently, low-CF NL neurons achieve a large contrast in ITD-tuning for loud sounds (Nishino et al., 2008). In this paper, we report a phasic inhibition of low-CF NL neurons that follows ipsilateral NM spikes with a short, fixed delay. This inhibition is likely mediated by the local GABAergic neurons that are sparsely distributed in and near the NM and NL (Carr et al., 1989; von Bartheld et al., 1989). Based on model simulations, we propose that the role of this feedforward inhibition is to improve ITD-tuning by creating a short time window of coincidence detection after the excitatory inputs from the ipsilateral NM. The combination of this feedforward phasic inhibition 
with the level-dependent sustained inhibition from the SON may allow the low-frequency NL neurons to acquire sensitivity to ITDs over a wide dynamic range of sound intensities.

Part of this study has been reported in abstract form (Yamada et al., 2009a,b).

\section{Materials and Methods}

Slice preparation and electrophysiological experiments. The animals were maintained and treated according to the regulations of the Animal Research Committee of Kyoto University and Nagoya University. The brain slices were prepared from chickens (Gallus domesticus) of either sex that were aged from postnatal day 1 (P1) to P7. Detailed brain slice preparation and maintenance procedures have been previously published (Kuba et al., 2003). During the experiments, the slices were continuously perfused with normal artificial CSF (ACSF) in the following (in mM): 125 $\mathrm{NaCl}, 2.5 \mathrm{KCl}, 26 \mathrm{NaHCO}_{3}, 1.25 \mathrm{NaH}_{2} \mathrm{PO}_{4}, 2 \mathrm{CaCl}_{2}, 1 \mathrm{MgCl}_{2}$, and 17 glucose, $\mathrm{pH}$ 7.4. The experiments were performed at chick body temperature $\left(40^{\circ} \mathrm{C}\right)$ unless otherwise stated. Whole-cell recordings were performed with a patch-clamp amplifier (EPC-8; HEKA Elektronik) under an upright microscope equipped with differential interference contrast optics (BX50WI; Olympus Optical) and an infrared-sensitive CCD camera (C5999; Hamamatsu Photonics). The patch pipettes were fabricated from thin-walled borosilicate glass capillaries (GC150TF-10; Harvard Apparatus) and had resistances of 2-3 M $\Omega$ when filled with a $\mathrm{KCl}$-based internal solution consisting of the following (in mM): $160 \mathrm{KCl}, 0.2$ EGTA, and 10 HEPES-KOH, pH 7.4. The pipettes were coated with a silicone resin (Sylgard; Dow Corning), and the tips were fire-polished before use. The electrode capacitance was compensated electronically, and the series resistance $(3-6 \mathrm{M} \Omega$ ) was compensated by $60-80 \%$. The liquid junction potential $(-3 \mathrm{mV})$ was corrected after the experiments. In some experiments, bicuculline ( $20 \mu \mathrm{M}$; Tocris Bioscience), gabazine (10 $\mu \mathrm{M}$; Tocris Bioscience), and 6,7-dinitroquinoxaline-2,3-dione (DNQX, $20 \mu \mathrm{m}$; Tocris Bioscience) were applied to the bath to block synaptic transmission. For electrical stimulation, biphasic square-wave voltage pulses (1-50 V, $0.1 \mathrm{~ms}$ duration) were applied through a bipolar tungsten electrode. These electrodes were placed at the ventral edge of the ipsilateral NM for ipsilateral stimulation and 50-100 $\mu \mathrm{m}$ ventral to the medial edge of the NL for contralateral stimulation (see Fig. 1C). The threshold stimulus intensities for the EPSC and the IPSC were determined separately as the minimum voltage that generated the synaptic responses in $>50 \%$ of stimuli (Fig. 1E).

Photolysis of caged glutamate (MNI-caged-L-glutamate; Tocris Bioscience) was used to stimulate local GABAergic neurons (see Fig. 4). The caged glutamate ( $5 \mathrm{~mm}$ in ACSF) was loaded into a glass pipette (tip diameter $<2$ $\mu \mathrm{m})$ and continuously applied to the targeted cells by pressure. A spontaneous decomposition of the compound during the positioning of the electrode was avoided by transillumination through a green interference filter (540$600 \mathrm{~nm}$ bandpass and $90 \%$ transmission; Nikon). Photolysis was performed with 330-385 nm UV light from a xenon short-ark lamp (75 W) through a dichroic mirror (400 nm cutoff; U-MWU2; Olympus Optical) and was controlled by mechanically opening a shutter in the light path; the area of UV illumination was narrowed to within a $50 \mu \mathrm{m}$ radius by the iris at the center of the visual field of the microscope. The uncaging experiments were performed at $20^{\circ} \mathrm{C}$ to obtain stable responses. The efficiency of photolysis was tested by measuring the AMPA-mediated currents that were evoked by the uncaging in whole-cell recorded NM neuron. When recorded neurons were directly UV illuminated, the uncaging generated AMPA-mediated currents with a latency of $4.5 \pm 0.3 \mathrm{~ms}$ (mean $\pm \mathrm{SE}$ ), and the current developed with a relatively slow time course ( $10-90 \%$ rise time, $13.9 \pm 1.7 \mathrm{~ms}, n=4$ cells). Thus, we adopted a UV flash duration of $20-30 \mathrm{~ms}$ in the uncaging experiments (Fig. 4). When the center of UV illumination was separated by $>50$ $\mu \mathrm{m}$ from the recorded neuron, the activated AMPA-mediated currents were reduced to $<10 \%$ of the maximum amplitude (data not shown). Thus, we concluded that the uncaging of the caged glutamate compound by UV flash was only effective in activating neurons located within a $50 \mu \mathrm{m}$ radius.

Data acquisition and analysis. The CF of each neuron was predicted from the mediolateral localization within the nucleus in coronal slices according to descriptions obtained from previous studies (Rubel and
Parks, 1975; Kuba et al., 2005), and we classified NL neurons into three CFs (high-CF, middle-CF, and low-CF neurons) and analyzed them separately. The current output from the patch-clamp amplifier was lowpass filtered at $5 \mathrm{kHz}$ (four-pole Bessel characteristics, UF-BL2; NF) and sampled at $10 \mathrm{kHz}$ with a 12-bit analog-to-digital converter (ADM8298BPC; Micro Science) using an in-house data acquisition program. Off-line analysis of the data was performed with commercially available software (AxoGraph; AxoGraph Scientific). The series resistance was monitored throughout each experiment, and changes $>20 \%$ resulted in discarding of the data. The decay kinetics of both the evoked and spontaneous IPSCs were fit with single- or double-exponential functions (Figs. 1 and 5). Fits were evaluated by the sum of the squared errors. The data are given as the mean \pm the SEM $(n=$ number of cells). Statistical significance was tested with Student's unpaired $t$ test unless otherwise stated.

Histological studies. In situ hybridization was performed for glutamic acid decarboxylase 1 (GAD1; Fig. 3 ) or for the $\alpha 1$-subunit of the GABA receptor (Fig. 5). Templates for the hybridization probes were designed according to the GenBank database sequences of chicken GAD1 (NM204913) and $\mathrm{GABA}_{\mathrm{A}}$ receptor $\alpha 1$ (NM204318). Probes were constructed using PCR and subcloned into pBluescript (Stratagene). The PCR primer pairs were the following: GAD1 forward, 5'-CGCACGGA TGCACCAGGAAG-3'; GAD1 reverse, 5' -AGAATCTGCTCCAGGGAC TC-3'; GABA $_{\mathrm{A}}$ receptor $\alpha 1$ forward, 5' -TGCCATGGATTGGTTTATAG C-3'; GABA ${ }_{\mathrm{A}}$ receptor $\alpha 1$ reverse, $5^{\prime}$-CCAACTCCACATCAATAACCT$3^{\prime}$. Digoxigenin (DIG)-labeled RNA probes were then synthesized by in vitro transcription with the DIG RNA labeling kit (Roche Products) according to the manufacturer's protocol.

The brainstems of P4-P14 chicks of either sex were dissected, frozen in an embedding medium (Tissue-Tek; Sakura Finetek) and sliced into 20 - $\mu \mathrm{m}$-thick coronal sections with a cryostat. The detailed hybridization procedures have been described previously (Yamada et al., 2005). For both probes, the hybridization and washout were conducted at 55 and $60^{\circ} \mathrm{C}$, respectively. The slices were immunoblotted with an anti-DIG antibody that was conjugated with alkaline phosphatase (1:2000 dilution) and visualized with the NBT/BCIP stock solution (Roche Products). The sense RNA was used as a control and no significant signals were detected. NeuroLucida 3.1 was used to plot the distribution of the GAD1-positive cells. We constructed a 3D serial distribution of GAD1positive cells around the NM and NL from a series of coronal slices ( $n=$ 2 chicks) and projected it onto a $2 \mathrm{D}$ plane (Fig. $3 E$; one chick). The mRNA expression of the $\alpha 1$-subunit of the $\mathrm{GABA}_{\mathrm{A}}$ receptor in the NM and three $\mathrm{CF}$ regions of NL were quantitatively measured using Image (NIH) (Fig. 5); the outline of the cell bodies was traced, and the density of staining within the selected area, including the nucleus, was measured, and were scaled relative to the background signal level in each slice.

Immunohistochemistry for GABA or Kv1.2 was performed as described previously (Yamada et al., 2005). A rabbit anti-GABA IgG (1: 1000 dilution; Sigma) was used to detect GABA immunoreactivity. The somatic area of the NL neurons was measured by immunostaining for Kv1.2 (mouse monoclonal IgG, 1:200 dilution; Millipore) as described by Kuba et al. (2005).

Model simulation. Neuronal modeling and simulation were performed with the NEURON 5.9 program based on the low-CF neuron model of the chick NL (Kuba et al., 2006; Nishino et al., 2008). The model consists of multiple sections: a soma ( $20 \mu \mathrm{m}$ in length and $10 \mu \mathrm{m}$ in diameter); two dendrites ( $200 \mu \mathrm{m}$ in length and $2 \mu \mathrm{m}$ in diameter); and an axon with a non-myelinated initial segment ( $25 \mu \mathrm{m}$ in length), 10 myelinated internodes, and 10 nodes of Ranvier. Based on the Web-accessible Model DB (Hines et al., 2004), we included a Hodgkin-Huxley type $\mathrm{Na}^{+}$current (Rothman and Manis, 2003), an $\mathrm{I}_{\mathrm{KLVA}}$, and an $\mathrm{I}_{\mathrm{KHVA}}$ (Rathouz and Trussell, 1998; Simon et al., 1999). The $\mathrm{I}_{\mathrm{KLVA}}$ and $\mathrm{I}_{\mathrm{KHVA}}$ were incorporated into the soma, dendrites, and the initial segment and nodes of the axon. The $\mathrm{Na}^{+}$current was added to the initial segment and nodes of the axon. The conductance of these currents was based on a previous NL model (Kuba et al., 2006), but $\mathrm{g}_{\mathrm{KLVA}}\left(0.0002 \mathrm{~S} / \mathrm{cm}^{2}\right)$ in the soma and dendrites was based on measurements obtained from the low-CF NL neurons (Kuba et al., 2005). The temperature was $40^{\circ} \mathrm{C}$ and the $\mathrm{Q}_{10}$ was 3.0. The time step of calculation was $12.5 \mu \mathrm{s}$. 


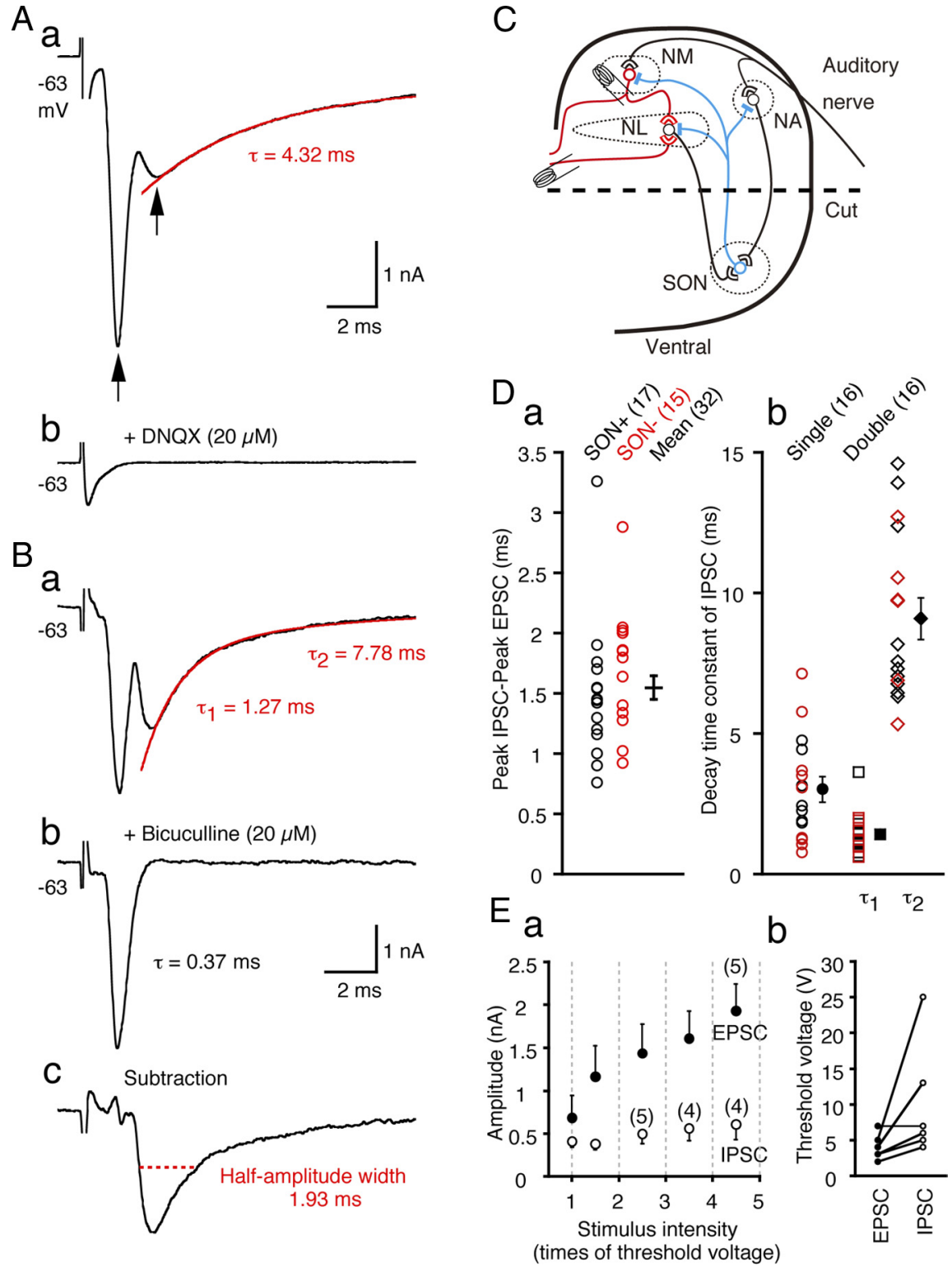

Figure 1. IPSCS are evoked by a local circuit in low-CF NL neurons. $A$, Representative traces of postsynaptic currents recorded from a low-CFNLneuron before $(\boldsymbol{a})$ and after $(\boldsymbol{b})$ bath application of DNQX $(20 \mu \mathrm{M})$. The arrows indicate the peak current responses. Application of DNQX eliminated both current responses. The red line is a single-exponential fit to the decay phase of the IPSC, and the decay time constant $(\tau)$ is indicated. $\boldsymbol{B}$, Synaptic currents recorded from another low-CF NL neuron before $(\boldsymbol{a})$ and after $(\boldsymbol{b})$ bath application of bicuculline $(20 \mu \mathrm{m})$ and the subtraction of $\boldsymbol{a}-\boldsymbol{b}(\boldsymbol{c})$. The red line is a double-exponential fit to the decay phase of the IPSC. The decay time constants of the IPSC $\left(\tau_{1}\right.$ and $\left.\tau_{2}\right)(\boldsymbol{a})$ and EPSC $(\tau)(\boldsymbol{b})$ are indicated. The red dotted line indicates the half-amplitude width of the isolated IPSC. C, A schematic drawing of the ITD coding circuit in the chicken brainstem. Excitatory terminals and inhibitory terminals are indicated by open and filled symbols, respectively. In some experiments, the ventral half of the coronal slices were dissected out to remove the projections from SON neurons (broken line labeled "cut"). D, IPSC delays relative to EPSC $(\boldsymbol{a})$ and IPSC decay time constants $(\boldsymbol{b})$ measured in intact slices (open black symbols) and slices after SON dissection (red symbols). No significant differences were observed between the two groups $(p>0.2)$, and the mean was calculated from the pooled data (filled symbols with error bars). The decay time courses of IPSCS of one group of neurons were fit with singleexponentials and those of the other group of neurons were fit with double-exponentials, and the time constants are plotted separately. The numbers in the parentheses are the numbers of cells in this and subsequent figures. Ea, The EPSC and IPSC amplitudes are plotted against the stimulus intensity, which was normalized to the threshold stimulus voltage. Amplitude of synaptic current was averaged within the interval indicated by the gray dotted lines and plotted at the center of the intervals. For samples smaller than six, sample numbers are in parentheses. Eb , The threshold stimulus intensities for the EPSCs and IPSCs are connected with solid line for individual neurons.

Excitatory inputs were made on each dendrite and the input timing of the two sides was displaced to mimic the ITD ( $\Delta t$ : ipsi-contra). A train of 20 stimuli with $5 \mathrm{~ms}$ intervals $(200 \mathrm{~Hz})$ was repeatedly applied, and the firing rate was calculated over an average of 10 trials. Moreover, each excitatory input consisted of multiple small EPSCs (15 EPSCs for each dendrite), and the input timing of each EPSC randomly varied from the onset of each cycle according to a normal distribution with an SD of $0.3 \mathrm{~ms}$. The randomness of the input timing of each EPSC mimicked the spike-time jitter of lowfrequency NM neurons (Fukui et al., 2006). Individual EPSCs had a profile based on the $\alpha$ function $\left(=g_{\text {syn }} t / \tau_{\text {syn }} \exp \left(1-t / \tau_{\text {syn }}\right)\right)$ and a time constant $\left(\tau_{\text {syn }} ; 0.32 \mathrm{~ms}\right)$ that corresponded to EPSCs in the low-CF neurons (Kuba et al., 2005). Spontaneous excitatory inputs with an average frequency of $200 \mathrm{~Hz}(20$ $\mathrm{nS}$ ) were added at random times that correspond to the spontaneous firing activity of NM neurons (Warchol and Dallos, 1990; Fukui et al., 2006). Inhibitory input was applied to the soma with a reversal potential of $-55 \mathrm{mV}$; although depolarizing GABA responses have been reported in the NL, these GABA responses most likely cause inhibition by conductance shunting (Hyson et al., 1995; Funabiki et al., 1998; Yang et al., 1999). The phasic IPSC was simulated by the $\alpha$ function, and the time constant was set to $1 \mathrm{~ms}$, which gave the halfamplitude width of $2.5 \mathrm{~ms}$ for the IPSCs, and was comparable to the half-amplitude width of evoked IPSCs in low-CF NL neurons; $2.49 \pm 0.33$ $\mathrm{ms}$ (Fig. $1 B c, n=8$ cells). The sustained feedback inhibition was included in the steady-state conductance. The normalized peak-trough contrast of the ITD-tuning curves (Fig. 7) was defined as the ratio of the firing rate difference between the peak (in-phase ITD, $\Delta t=0 \mathrm{~ms}$ ) and the trough (the ITD that produces the firing rate minimum) to the firing rate at the peak.

\section{Results}

\section{Local stimulation of NM fiber} projections evoked both EPSCs and IPSCs in low-CF NL neurons

We recorded NL neurons with patch pipettes filled with a $\mathrm{KCl}$-based internal solution; thus, the reversal potential was expected to be near $0 \mathrm{mV}$ for both IPSCs and EPSCs. We categorized the NL into three CF regions as previously reported (Rubel and Parks, 1975; Kuba et al., 2005). In low-CF NL neurons, we frequently observed a slow inward current that followed the fast inward current when the ipsilateral NM projection fibers were stimulated (Fig. 1Aa, two arrows). Both components were blocked by bath-applied DNQX (20 $\mu \mathrm{M}$; Fig. $1 A b, n=8)$. Only the slow component was blocked by bicuculline (20 $\mu \mathrm{M}$; Fig. $1 \mathrm{Bb})$ or gabazine $(10 \mu \mathrm{M}$; data not shown). Therefore, the fast component was an EPSC, and the slow component was a GABAergic IPSC that was activated through excitatory synapses, namely the activation of some inhibitory interneurons. The decay phase of the IPSCs was best fit in half of the neurons by a single-exponential function (decay time constant $=$ $3.02 \pm 0.45 \mathrm{~ms}, n=16$; Fig. $1 \mathrm{Aa}$ ) and by a double-exponential 
Table 1. Summary of evoked IPSC properties in low-CF NL neurons

\begin{tabular}{|c|c|c|c|c|c|}
\hline & \multirow{2}{*}{$\begin{array}{l}\text { Amplitude } \\
(\mathrm{nA})\end{array}$} & \multicolumn{4}{|c|}{ Decay time constants } \\
\hline & & $\tau_{1}(\mathrm{~ms})$ & $\tau_{2}(\mathrm{~ms})$ & $\% \tau_{1}$ & $\% \tau_{2}$ \\
\hline \multicolumn{6}{|l|}{ Evoked IPSC } \\
\hline $\begin{array}{c}\text { Single-exponential } \\
\text { fit }(n=16)\end{array}$ & $0.75 \pm 0.14$ & $3.02 \pm 0.45$ & & & \\
\hline $\begin{array}{l}\text { Double-exponential } \\
\qquad \text { fit }(n=16)\end{array}$ & $1.10 \pm 0.20$ & $1.41 \pm 0.18$ & $9.09 \pm 0.74$ & $41.0 \pm 4.0$ & $59.0 \pm 4.0$ \\
\hline
\end{tabular}

function in the other half $(1.41 \pm 0.18$ and $9.09 \pm 0.74 \mathrm{~ms}, n=$ 16; Fig. $1 B a, D b$; Table 1). The current trace shown in Figure $1 B c$ was the isolated IPSC component by subtraction of the trace after application of bicuculline (Fig. $1 B b$ ) from the original trace (Fig. $1 B a$ ). The decay time course of these isolated IPSCs was similarly fit either by a single-exponential function (decay time constant $=$ $3.03 \pm 0.76 \mathrm{~ms}, n=5)$ or double-exponential function (1.42 \pm 0.12 and $10.1 \pm 2.0 \mathrm{~ms}, n=3)$. These time constants were not different from those measured in the original IPSC traces $(p>$ 0.6 ). The half-amplitude width measured from the isolated IPSCs was $2.49 \pm 0.33 \mathrm{~ms}(n=8)$, which was not significantly different between two fitting groups: $2.56 \pm 0.48 \mathrm{~ms}$ and $2.37 \pm 0.48 \mathrm{~ms}$, single-exponential fit group and double-exponential fit group, respectively $(p>0.8)$. In high-CF and middle-CF neurons, we did not observe IPSCs that followed the EPSCs $(n=10$ for high-CF and $n=11$ for middle-CF neurons). Furthermore, these IPSCs were not generated by stimulation to the contralateral NM projection $(n=10)$.

Electrical stimulation of the NM fibers might activate excitatory synapses from the NL to the $\mathrm{SON}$, a nucleus that inhibits the NM, NL, and NA (Fig. 1C). Thus, we dissected out the ventral half of the slice preparation to remove the SON (Fig. 1C, broken line). In the absence of the SON, this slice continued to produce both EPSCs and IPSCs upon stimulation of the NM projection $(n=$ $15)$, and bath-applied DNQX eliminated both EPSCs and IPSCs $(n=5)$. A nearly equal percentage of tested cells in the intact control slices and the SON dissected slices generated IPSCs: 55\% $(17 / 31)$ of cells in the intact slices and $58 \%$ (15/26) of cells in the SON dissected slices. We also found that the IPSC amplitude was slightly smaller in slices after SON dissection (61\%; $1.14 \pm 0.19$ $\mathrm{nA}$ in the intact and $0.69 \pm 0.12 \mathrm{nA}$ in SON dissected slices; $p=$ $0.07)$; however, this was proportional to the reduction in the EPSC amplitude $(62 \% ; 2.02 \pm 0.38 \mathrm{nA}$ in the intact and $1.26 \pm$ $0.27 \mathrm{nA}$ in the SON dissected slices; $p=0.12$ ). Furthermore, the time delay of the IPSC to the EPSC (measured at the peak) showed no significant difference between these two groups (Fig. $1 \mathrm{Da}$; control, black; SON dissection, red; $p=0.25$ ). The decay time constants showed no significant differences between the intact and SON dissected slices (Fig. 1Db; control, black; SON dissection, red; $p>0.9$ ). Moreover, electrical stimulation applied to NA in the intact slice did not generate any IPSCs in NL neurons ( $n=16$ cells), and in slices after cutting out the NA region, stimulation of NM projection generates IPSCs that followed EPSCs $(n=5)$, and both EPSCs and IPSCs were blocked by bath-applied DNQX $(n=3)$; namely the possibility that IPSCs were generated through stimulation of auditory nerve fibers (ANFs) that activated the NA pathway (Fig. 1C) is negligible. We therefore concluded that these IPSCs were most likely generated through activation of GABAergic neurons near the NL.

With increases in stimulus intensity, the amplitudes of the EPSCs increased and reached a maximum $>4$ times that of the threshold response $(4.6 \pm 1.2$ times), whereas the IPSC amplitudes remained nearly constant $(1.5 \pm 0.2$ times, $n=6$; Fig. $1 E a)$. This result may indicate that the inhibitory innervations to a single NL neuron are limited in number and may further indicate that not all NM neurons innervate the local GABAergic neurons. Thus, the large difference in threshold stimulus intensity between the EPSCs and IPSCs that was observed in some neurons (Fig. $1 E b)$ may be attributed to the pattern of NM innervation to the local GABAergic neurons and, partly, to the cutting of synaptic connections by slicing.

\section{Temporal relationship of EPSCs and IPSCs}

Every IPSC followed the EPSC with a delay of $1-2 \mathrm{~ms}$ (Fig. 1Da; $1.55 \pm 0.10 \mathrm{~ms}, n=32$, measured as the time difference of the two peaks) when the stimulus intensity was sufficiently high, and the temporal jitter of IPSCs, defined as the SD of the peak time, was small $(0.21 \pm 0.04 \mathrm{~ms}$, calculated from cell data that included $>10$ successful traces, $n=7)$. Furthermore, the delay from the EPSC to the IPSC was comparable to the delay from the stimulation to the EPSC $(1.45 \pm 0.18 \mathrm{~ms}, n=8)$.

We further examined the temporal relationship between EPSCs and IPSCs by applying a tetanus stimulus to the projection from the ipsilateral NM $(100-500 \mathrm{~Hz}$, Fig. 2). The IPSCs followed the EPSCs in a one-to-one manner throughout the train of 10 stimuli when stimulated at $200 \mathrm{~Hz}$ (Fig. 2A, arrows). The IPSCs were evoked with high fidelity $(>80 \%)$ in response to lowfrequency stimulation $(100-333 \mathrm{~Hz})$; although, the fidelity was sharply reduced at $500 \mathrm{~Hz}$ (Fig. 2B). Figure 2Ca plots the peak times of EPSCs and IPSCs for the first and tenth stimulation of the $200 \mathrm{~Hz}$ train. Between the first and tenth stimulation, the delays between the EPSC and IPSC were not different (1.74 \pm 0.15 and $1.53 \pm 0.13 \mathrm{~ms}, n=10$, for the first and tenth IPSC, respectively; $p>0.3)$ and the temporal jitter of the peak time of IPSC was not different $(0.25 \pm 0.05$ and $0.26 \pm 0.05 \mathrm{~ms}, n=10$; $p>0.9)$. Moreover, these time-locked properties of IPSC to EPSC were not affected by tetanus frequency from $100-333 \mathrm{~Hz}$. Figure $2 \mathrm{Cb}$ shows the delay of IPSC from the EPSC and its fluctuation (defined as the SD of the delay times in each cell), and these two parameters were not different between the first and tenth stimulation during the tetanus of 100-333 Hz. The absolute value of the jitter of the EPSC-IPSC delay was $0.27 \pm 0.05 \mathrm{~ms}$ $(n=10)$. These results indicated that the local GABAergic neurons precisely tracked the ipsilateral NM spikes, and these observations are not inconsistent with the conclusion that the NM neurons innervate the local GABAergic neurons monosynaptically. Similar high-fidelity transmission of small timing jitter has been observed in central monosynaptic transmission when stimulus intensity and frequency are manipulated (Renshaw, 1940; Curtis and Eccles, 1960).

\section{Effects of repetitive stimuli on the amplitudes of EPSCs and IPSCs}

Repetitive stimulation resulted in the progressive depression of EPSC amplitudes (Fig. 2A), and the level and rate of depression increased with the stimulus frequency (Fig. 2D). IPSC amplitudes were also depressed with repetitive stimulation (Fig. 2E, 200-333 $\mathrm{Hz}$ ), whereas a small facilitation was observed when the stimulation was applied at a lower frequency $(100 \mathrm{~Hz})$. During the repetitive stimulation, the total synaptic current increased through the accumulation (Fig. $2 A$, broken lines indicate the residual current level preceding individual IPSCs). The EPSC kinetics was so fast that the current accumulation was most likely due to the pro- 

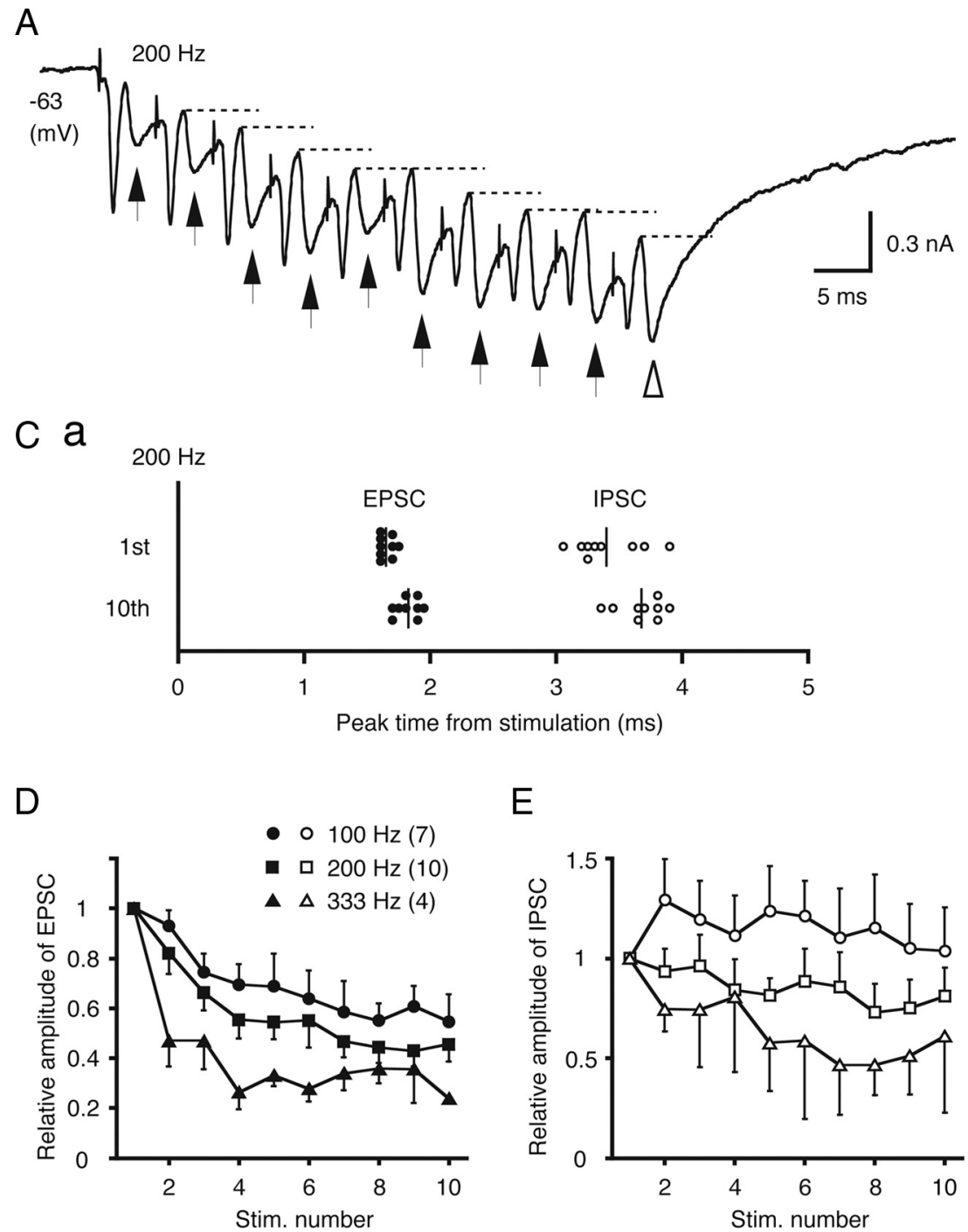

E

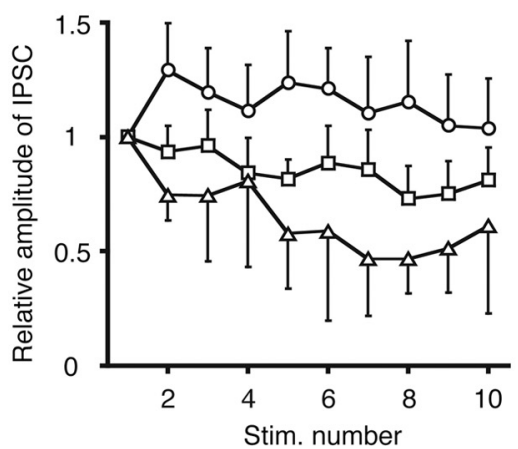

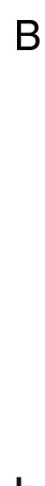

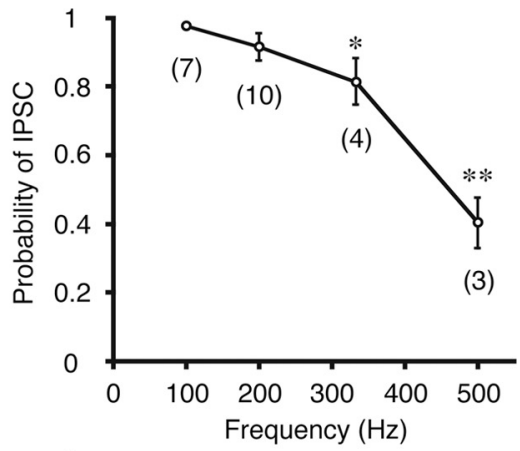

b

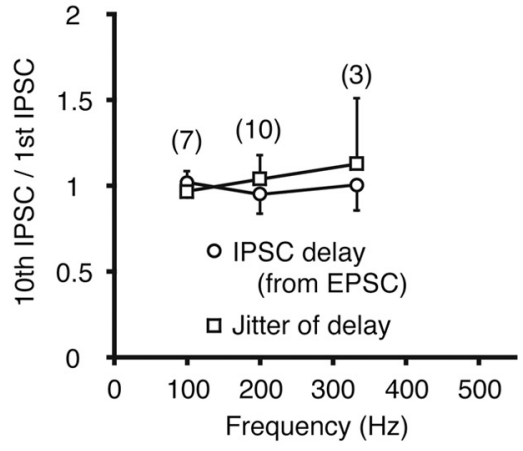

$\mathrm{F}$

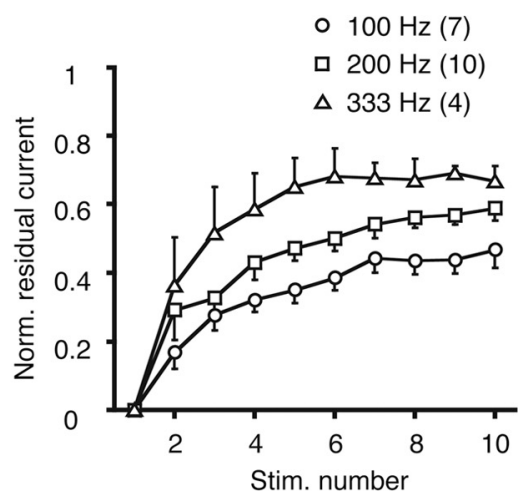

Figure 2. IPSCs precisely follow EPSCs during repetitive, low-frequency stimulation. $A$, The postsynaptic currents of low-CF neurons elicited by 10 stimuli at $200 \mathrm{~Hz}$. This trace represents the average of five trials. The arrows indicate the IPSCS and the broken lines indicate the residual component of the inhibitory currents in each cycle. $\boldsymbol{B}$, The probabilities of detecting IPSCs for each stimulation were measured for each trial and averaged. The statistical significance is indicated by ${ }^{*} p<0.05$ or ${ }^{* *} p<0.01$ in this and subsequent figures. Ca, The peak times of EPSCs and IPSCs relative to each stimulation are plotted for first and tenth stimulations of the train. Samples from a single cell are represented, and this cell is different from that in $\boldsymbol{A}$. Vertical lines indicate the averages of each peak time. $\boldsymbol{C} \boldsymbol{b}$, The IPSC delay relative to the EPSC and the fluctuation of the IPSC delay were compared between the first and tenth stimulations (tenth/first) at different stimulus frequencies $(100-333 \mathrm{~Hz})$. D, The EPSC amplitudes normalized to the first EPSC are plotted against the stimulus number in the train. $\boldsymbol{E}$, The IPSC amplitudes, normalized to the first IPSC. $\boldsymbol{F}$, The accumulated currents were measured from the baseline to the start of each IPSC (indicated by broken lines in $\boldsymbol{A}$ ), and normalized to the maximum amplitude of the total synaptic current (open arrowhead in $\boldsymbol{A}$ ).

longed time course of the IPSCs. Figure $2 F$ illustrates the acceleration of current accumulation with stimulus frequency.

\section{Local GABAergic neurons were clustered around the low-CF region of the $\mathrm{NL}$}

Using in situ hybridization, we examined the distribution of GABAergic neurons in the NM and NL, particularly along the tonotopic axis of the NL. Coronal slices (20 $\mu \mathrm{m}$ thick) were hybridized with a probe that detected GAD1 mRNA (Fig. 3). GAD1-positive cells were rarely observed in the high-CF and middle-CF regions (Fig. $3 A, B$ ). In contrast, many GAD1positive cells were found in the low-CF region (Fig. $3 C$ ). The GAD1-positive cells were clustered in the areas between the $\mathrm{NM}$ and NL (Fig. $3 \mathrm{Ca}$ ), within the NL and lateral to the NL (Fig. 3Cb). These observations are consistent with previous reports describing clusters of GABAergic neurons (Carr et al.,
1989; von Bartheld et al., 1989). We did not count the GAD1positive cells that were distributed medially to the NM regions of low-CF because they were located in and near the medial vestibular nucleus (MVN, Fig. 3Cb). The tonotopic distribution of the GAD1-positive cells indicated that cell density increased in the caudal direction (Fig. $3 E$ ). We divided the NL into three separate CF regions (Fig. $3 E$, dashed lines), and nearly $80 \%$ of the GAD1-positive cells were found in the low-CF NL region (Fig. $3 F ; n=2$ chicks).

Dense GABA immunoreactivity was found in the fibers and terminals in the low-CF NL region (Fig. 3G; same level as Fig. $3 C b$, but only the lateral part is shown). However, GABA immunoreactivity in the cell bodies was clustered in the lateral border of the NL. These GABA-immunoreactive cells were small compared with the low-CF NL neurons that were immunostained with Kv1.2 (the somatic area was $144 \pm 6.9 \mu \mathrm{m}^{2}$ for GABA- 

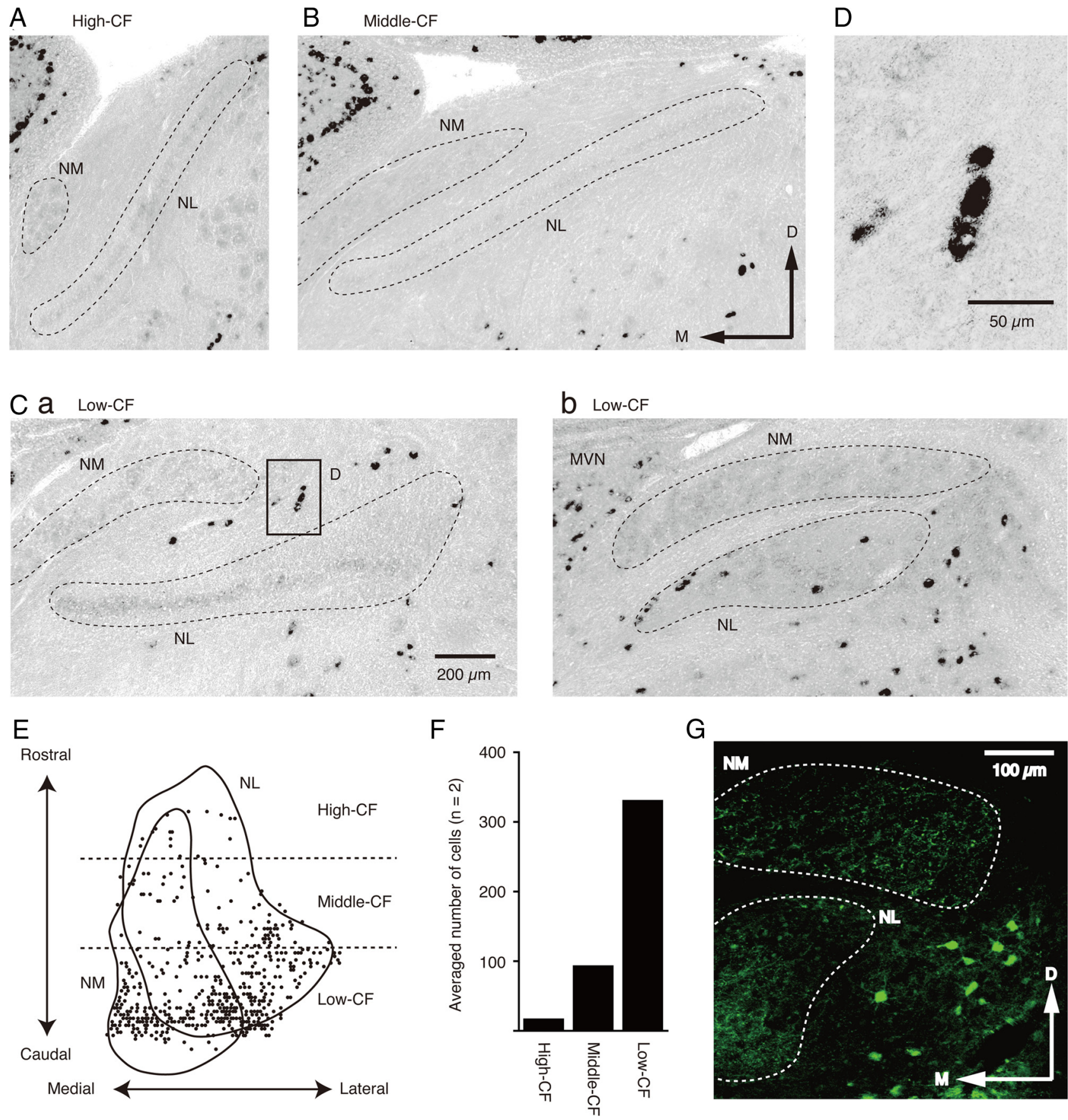

Figure 3. GABAergic neurons are clustered in the low-CF region of the NL. $A-C$, Distributions of GAD1 mRNA-positive cells detected by in situ hybridization. The slices contain high-CF ( $A$ ), middle- $C F(\boldsymbol{B})$, and low-CF $(\boldsymbol{C})$ regions of the NL. The broken lines indicate areas of the NM and NL. $\boldsymbol{D}$, High magnification of the box in $\boldsymbol{C a}$. $\boldsymbol{E}$, Two-dimensional distribution of GAD1 mRNA-positive cells in and around the NM and NL. $\boldsymbol{F}$, The average number of GAD1 mRNA-positive cells around each (F region of the NL (separated by broken lines in $\boldsymbol{E}$ ). $\boldsymbol{G}$, Immunoreactivity to the GABA antibody in the lateral parts of the NM and NL regions. The rostrocaudal level of the slice is the same as that in $\mathbf{C b}$.

positive neurons $(n=91)$ and $300 \pm 5.3 \mu \mathrm{m}^{2}$ for low-CF NL neurons $(n=216), p<0.01)$.

\section{Local GABAergic neurons innervated low-CF NL neurons}

We reasoned that these local GABAergic neurons might be the source of the IPSCs shown in Figures 1 and 2. We tested this hypothesis with focal application of glutamate in the region outside the low-CF NL. We released caged glutamate using a UV flash applied through the objective lens at focal sites. The exposed area was limited (50 $\mu \mathrm{m}$ radius; see Materials and Methods) but appropriate for the simultaneous activation of small numbers of
GABA neurons (Fig. 3G). The UV flash was applied $>100 \mu \mathrm{m}$ lateral to the whole-cell patch-clamped NL neuron (Fig. $4 A$ ). Under this condition, the UV flash did not affect the baseline currents but only generated transient currents in the NL neurons; thus uncaging of the caged glutamate compound did not activate AMPA receptors in the NL neurons. The uncaging evoked transient inward currents in low-CF NL neurons (Fig. 4B,C). Most currents were generated $\sim 20-30 \mathrm{~ms}$ after the onset of the UV flash ( $22.9 \pm 1.3 \mathrm{~ms}, n=3$ cells $)$, declined with a relatively slow time course (decay time constant; $15.6 \pm 7.4 \mathrm{~ms}$ ), and were blocked by bath-applied bicuculline (Fig. $4 B$, bottom trace). 


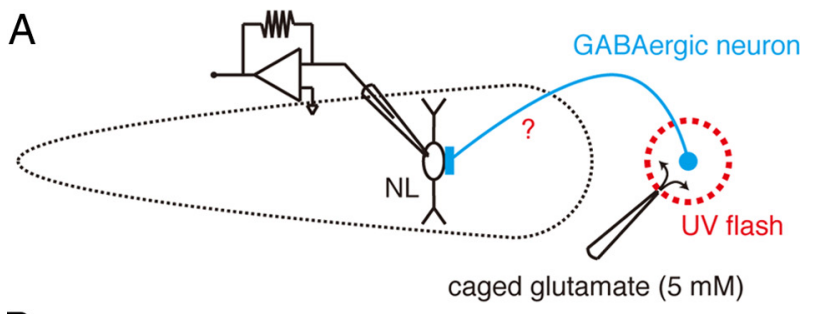

B

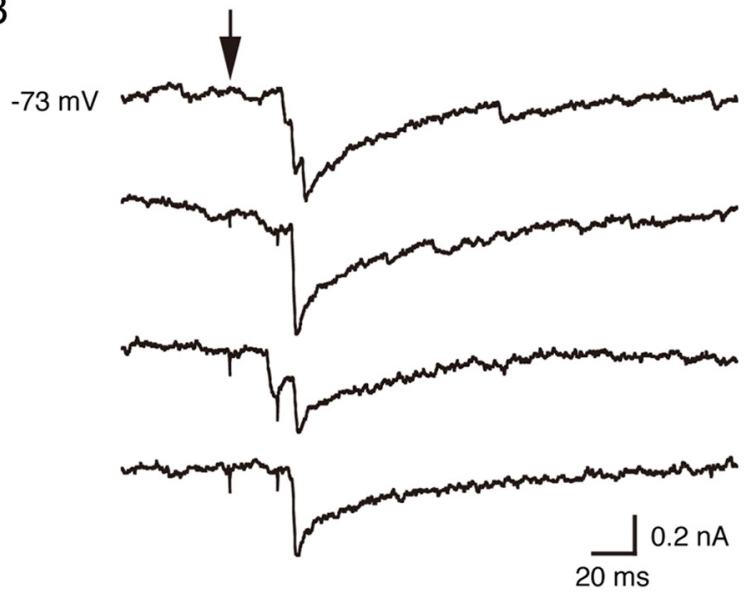

Bicuculline $(20 \mu \mathrm{M})$

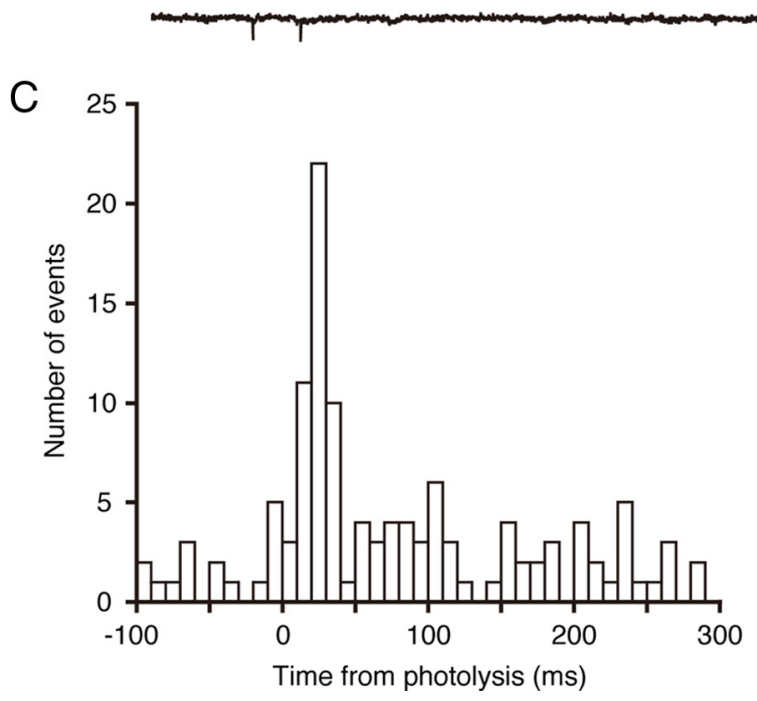

Figure 4. Photoactivation of local GABAergic neurons. $A$, A schematic drawing of the experimental procedure. A UV flash was applied to release glutamate by uncaging in the area lateral to the low-CF region of the NL. The current responses were recorded from low-CF NL neurons. $\boldsymbol{B}$, A series of current responses in a low-CF NL neuron before (4 top traces) and after (bottom trace) application of bicuculline. The time of photoactivation is indicated with an arrow. The recording temperature was $20^{\circ} \mathrm{C}$. C, A peristimulus time histogram of the events measured in the recording of $\boldsymbol{B}$. The spontaneous events are included.

These results indicate that local GABAergic neurons formed inhibitory synapses on low-CF NL neurons. The presence of several steps in the photoactivated current responses (Fig. 4B) suggests that a small number of local GABAergic neurons might converge on a single low-CF NL neuron. The relatively long delay of the photoactivated currents compared with the delay from ipsilateral EPSCs to IPSCs (Fig. 1Da) might be due to the slow development of uncaging (see Materials and Methods).

We also tried to detect the synaptic connections between these local GABAergic neurons and NL neurons by labeling projections of local GABAergic neurons or paired patch recording in slice preparations, but these were unsuccessful. This might be because the heavy myelination in post-hatch animals used in this study limited our recordings to neurons located near the surface of slices, while the uncaging photostimulation can activate a group of neurons located in a deep layer of slices.

\section{The IPSC time course was faster in low-CF than middle-CF and high-CF neurons}

Spontaneous IPSCs (sIPSCs) measured in low-CF neurons exhibited faster decay kinetics than those measured in the middle-CF and high-CF neurons (Fig. 5). Figure 5A shows representative traces of currents recorded in high-CF (Fig. 5Aa) and low-CF neurons (Fig. 5Ab). For comparison, we superimposed two ensemble-averaged traces after normalization (Fig. 5Ac). Most sIPSCs (>95\%) were best fit by a single-exponential function (Fig. $5 A c$ ), and the average decay time constant was approximately four times smaller in the low-CF neurons than in the high-CF and middle-CF neurons (Fig. $5 C c ; p<0.01$ ). Cumulative histograms indicated that the decay time constants of all sIPSC were within $15 \mathrm{~ms}$ in the low-CF NL neurons (Fig. 5B). Furthermore, nearly $80 \%$ of the sIPSCs were distributed in a range smaller than the averaged decay time constant $(4.90 \pm 0.65$ ms; Fig. $5 B$, arrow). The fast decay of sIPSC in the low-CF NL neurons was still slower than the fast decay component of evoked IPSCs (Fig. 1Db; Table 1). This is partly because the majority of inhibitory synapses on the low-CF NL neurons should be originated in the SON (Nishino et al., 2008) and sIPSC could be generated from different group of neurons from the local GABAergic neurons. The sIPSC might have some asynchronous components of the transmitter release also (Tang and Lu, 2012, see Discussion). In the high-CF and middle-CF neurons, most IPSCs had a decay time constant slower than $5 \mathrm{~ms}$ (Fig. 5B). The mean amplitudes and $10-90 \%$ rise times were not significantly different between the three categories of CF neurons (Fig. $5 \mathrm{Ca}, \mathrm{Cb} ; \mathrm{p}>0.4$ ).

Subunit composition is known to have a strong influence on

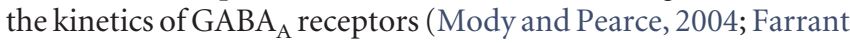
and Nusser, 2005). The presence of the $\alpha 1$-subunit in $\mathrm{GABA}_{\mathrm{A}}$ receptors accelerates the decay kinetics (McClellan and Twyman, 1999; Vicini et al., 2001; Goldstein et al., 2002; Eyre et al., 2012). In situ hybridization demonstrated a relatively high level of expression of the mRNA encoding the $\mathrm{GABA}_{\mathrm{A}} \alpha 1$ receptor subunit in the caudolateral NL regions where the low-CF neurons are found (Fig. 5E, F). However, this expression diminished toward the rostromedial NL regions where the high-CF (Fig. 5D) and middle-CF neurons (Fig. 5E, medial side) are found. Expression level of the mRNA was significant in the low-CF neurons (1.66 \pm 0.08 , relative to the back ground, $p<0.01$ ) but not in the other CF neurons $(1.03 \pm 0.01$ for high-CF and $1.17 \pm 0.06$ for middle-CF neurons, $n=3$ chicks). In contrast, expression of the $\alpha 1 \mathrm{GABA}_{\mathrm{A}}$ receptor subunit was nearly absent in the $\mathrm{NM}(1.15 \pm$ 0.02 ; Fig. $5 E, F)$.

\section{Sustained and phasic inhibition may enhance the contrast of ITD-tuning}

Based on the hypothesis that local GABAergic neurons produce a phase-locked inhibition on low-CF NL neurons, we used model simulations to explore how this phasic inhibition affects ITDtuning (Fig. 6, 7).

Bilateral EPSC inputs that corresponded to a sinusoidal sound of $200 \mathrm{~Hz}$ were applied to the two dendrites of the model neuron. We calculated the firing rate as a function of the ITD by changing the time difference between the EPSC inputs $(\Delta t)$. Two modes of inhibitory inputs were then delivered to the soma: a sustained 
inhibition that mimicked the inhibition from the SON neurons and a phasic inhibition that mimicked the inhibition from the local GABAergic neurons. The phasic IPSC was delivered $1 \mathrm{~ms}$ after the ipsilateral EPSC (Fig. 1Da), and the time constant of the $\alpha$ function was $1 \mathrm{~ms}$ (see Materials and Methods).

First, we separately examined the effects of sustained and phasic inhibition on both the low-level (60 nS; Fig. 6A-C) and high-level (90 nS; Fig. 6D-F) excitatory inputs. In the absence of inhibition (Fig. $6 A, D)$, both the in-phase ITD $(\Delta t=0 \mathrm{~ms}$, left) and out-of-phase ITD ( $\Delta t=2 \mathrm{~ms}$, right) showed robust spike activities. Thus, the peak-trough contrast of the ITD-tuning curve was low (note the peaktrough contrast here is the firing rate difference between the two symbols $\bigcirc$ and $\square$, Fig. $6 G$ ). At a high level of excitatory input, the action potentials were generated by the unilateral EPSPs alone, and the firing rate increased at the out-of phase ITDs (Fig. 6G, gray line). Next, we separately added sustained (Fig. $6 B, E$ ) and phasic inhibitions (Fig. 6C,F) of $300 \mathrm{nS}$. This level of inhibitory conductance induced substantial inhibitory effects on the ITD-tuning curves. During low-level excitatory input, the firing rate was suppressed at the out-of-phase ITD regardless of the mode of inhibition (Fig. $6 B, C$, right). Moreover, the sustained inhibition was similarly effective in reducing spike generation at the in-phase ITD (Fig. 6B, left), which reduced the peak-trough contrast of the ITD-tuning (Fig. $6 \mathrm{H}$, black line). In contrast, the phasic inhibition did not affect the firing activity of the in-phase ITD but suppressed the out-of-phase spikes (Fig. 6C). Accordingly, the firing activities of the early phase of the cycle were highly preserved (Fig. 6C, left, bottom period-histogram); this produced a high contrast in the ITD-tuning when the input excitatory level was low (Fig. 6I, black line).

When the excitatory input level was high, the sustained inhibition did not effectively suppress firing at the in-phase ITD, while it did suppress firing at the out-of-phase ITD (Fig. 6E). This produced a high peak-trough contrast in the ITD-tuning (Fig. $6 \mathrm{H}$, gray line). In contrast, the phasic inhibition had little effect on the firing activity at the early phase of the cycle for both in-phase and out-ofphase ITDs (Fig. 6F), and the peaktrough contrast was low (Fig. 6I, gray line). Thus, a high contrast in ITD-tuning could be achieved with phasic inhibition for the low-level excitatory inputs (Fig.
A

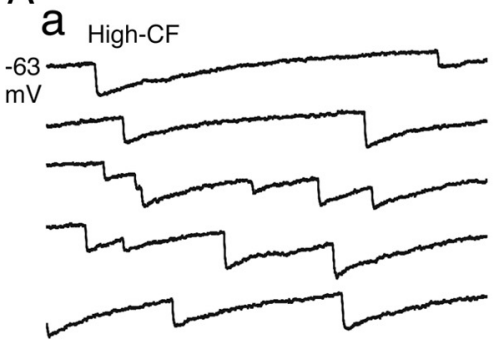

C
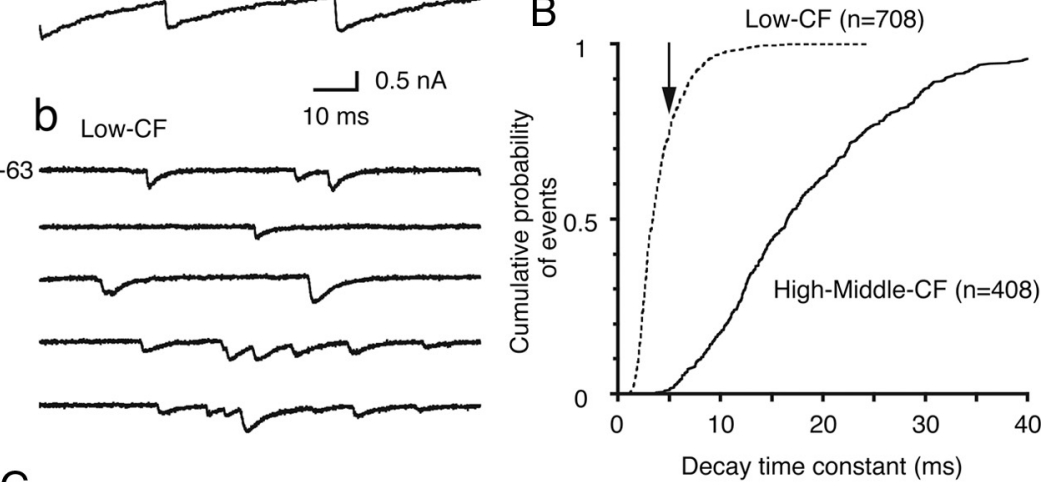

C

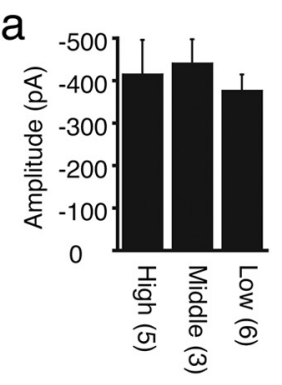

b
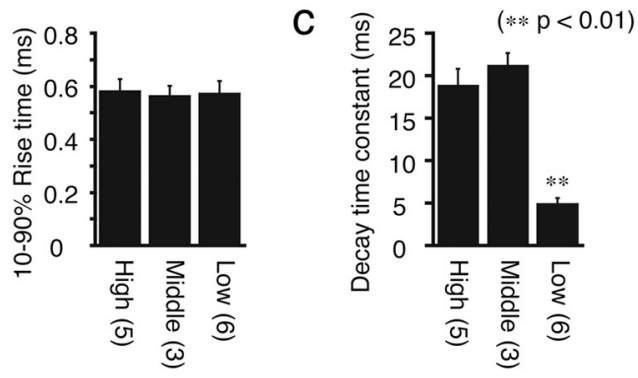

D High-CF

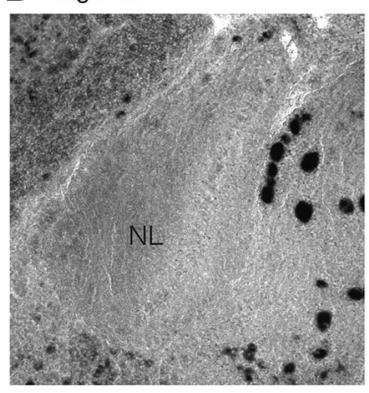

E Middle-Low-CF

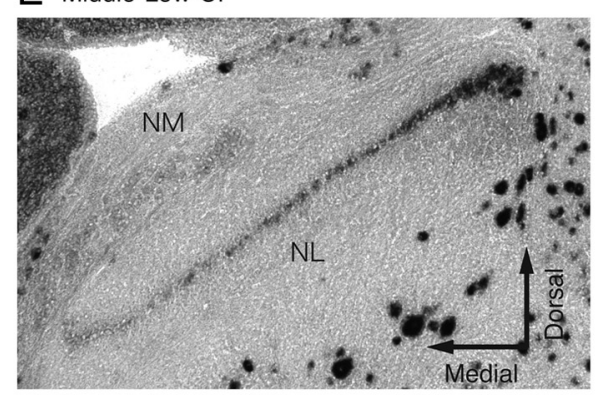

$F_{\text {Low-CF }}$

G
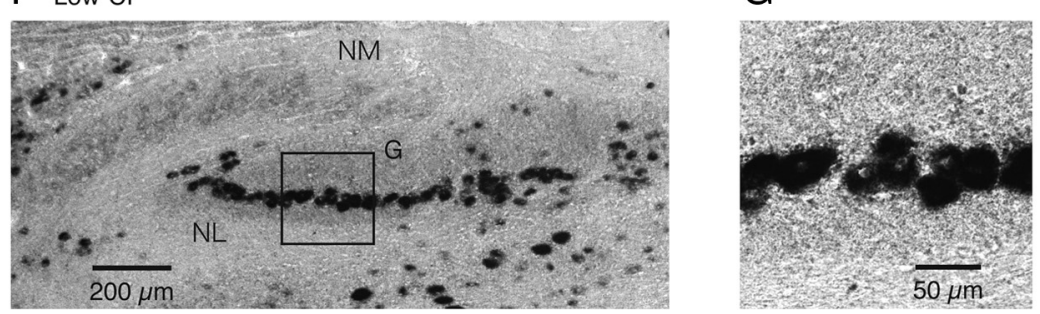

Figure 5. Fast decay kinetics of sIPSCS and strong expression of the $\mathrm{GABA}_{\mathrm{A}}$ receptor $\alpha 1$-subunit in low-CF neurons. $\boldsymbol{A}$, Representative traces of sIPSC recorded from a high-CF $(\boldsymbol{a})$ and a low-CF $(\boldsymbol{b})$ neuron. SIPSCs from these two neurons were extracted, ensemble-averaged, and superimposed after normalization (c). The gray lines are the single-exponential fit to the decay time course. $\boldsymbol{B}$, Cumulative probability plots of the sIPSC decay time constants sampled from high-CF and middle-CF (solid line; 408 events from 8 cells) and low-CF (broken line; 708 events from 6 cells) neurons. The arrow indicates the averaged time constant of the low-CFneurons. C, Averaged sIPSC values including the amplitude (a), $10-90 \%$ rise time $(\boldsymbol{b})$, and decay time constant (c), were compared among the high-CF, middle-CF, and low-CFneurons. The decay time constant of the low-CF neurons was significantly different from the other CF neurons $(p<0.01)$. $\boldsymbol{D}-\boldsymbol{F}$, The expression patterns of the $\mathrm{GABA}_{\mathrm{A}}$ receptor $\alpha 1$-subunit mRNA as detected by in situ hybridization. Representative coronal slices that comprise the high-CF $(\boldsymbol{D})$, middle-low-CF $(\boldsymbol{E})$, and low-CF $(\boldsymbol{F})$ regions of the NL. The lower CF regions in the NL were close to the lateral edge (Rubel and Parks, 1975). G, High magnification of the box in $\boldsymbol{F}$. 

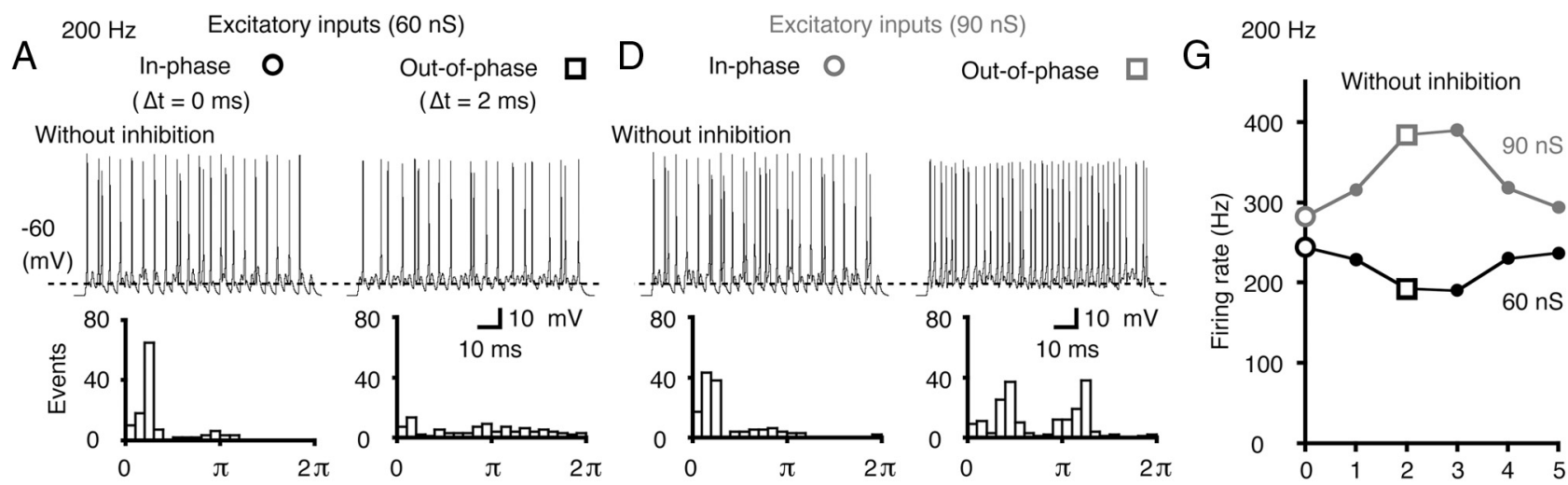

B
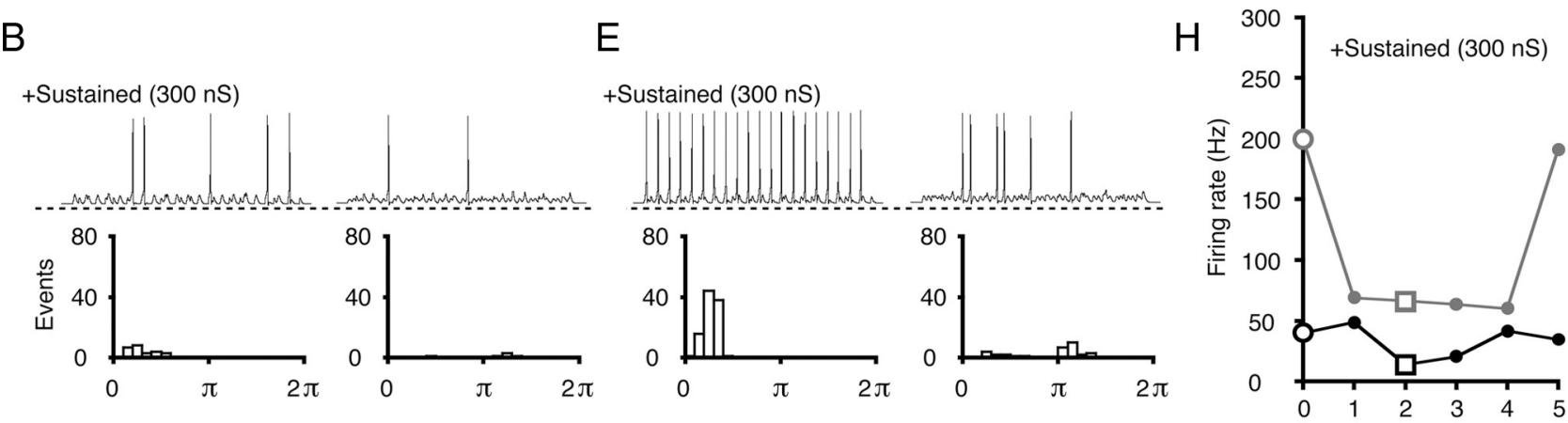

\section{$\mathrm{F}$}
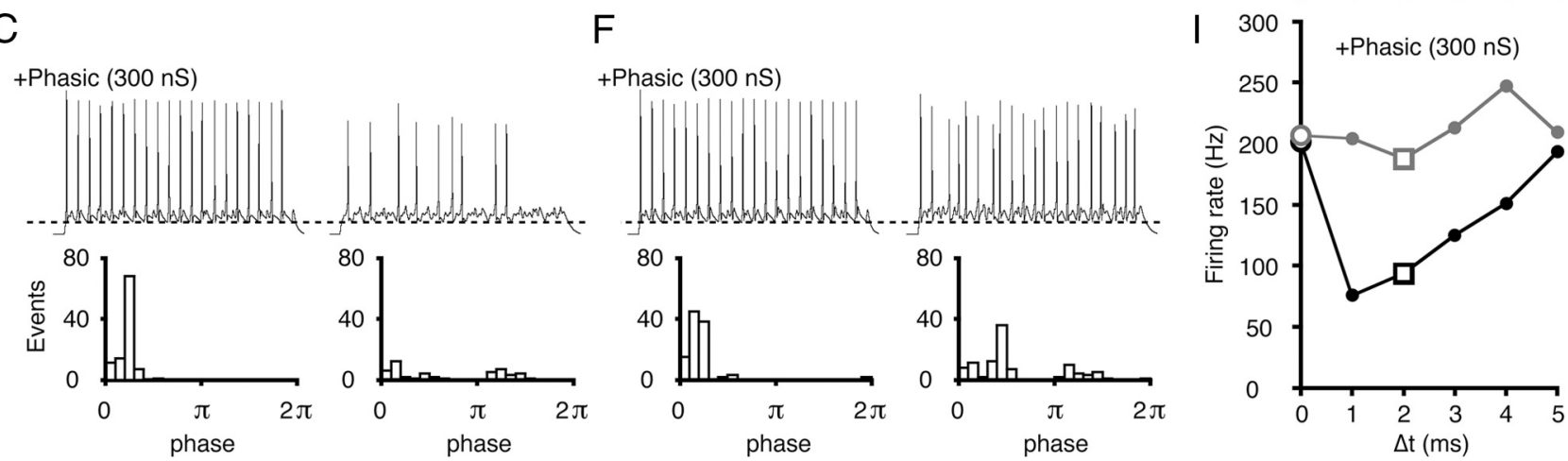

Figure 6. Model simulation of sustained and phasic inhibition in low-CF neurons. $\boldsymbol{A}-\boldsymbol{F}$, The simulated firings of a model neuron with low-level $(60 \mathrm{nS} ; \boldsymbol{A}-\boldsymbol{C})$ and high-level $(90 \mathrm{nS} ; \boldsymbol{D}-\boldsymbol{F})$ excitatory inputs. Bilateral excitatory inputs were applied in-phase (left, $\Delta t=0 \mathrm{~ms}$ ) or out-of-phase (right, $\Delta t=2 \mathrm{~ms}$ ) ITDs. $\boldsymbol{A}, \boldsymbol{D}$, No inhibition was applied. $\boldsymbol{B}, \boldsymbol{C}, \boldsymbol{E}, \boldsymbol{F}$, Inhibition was applied at $300 \mathrm{nS}$. Sustained inhibition $(\boldsymbol{B}, \boldsymbol{E})$ or phasic inhibition $(\boldsymbol{C}, \boldsymbol{F})$ was separately applied. Representative traces (top) and period histograms of spike activity (bottom) are shown in each condition. The broken lines in each trace indicate a voltage level of $-60 \mathrm{mV}$. The period histograms combine the data from five trials of a stimulus train $(200 \mathrm{~Hz} ; 5 \mathrm{~ms}$ corresponded to one cycle, $2 \pi)$. $\mathbf{G}-I$, The firing rates were plotted as a function of $\Delta t$ (ITD-tuning curve) for both the low-level ( $60 \mathrm{nS}$, black lines) and high-level ( $90 \mathrm{nS}$, gray lines) excitatory inputs without inhibition $(\boldsymbol{G})$, with sustained inhibition $(\boldsymbol{H})$, and with phasic inhibition $(\boldsymbol{I})$. The two open symbols $(\bigcirc, \square)$ correspond to $\Delta$ t shown in $\boldsymbol{A}-\boldsymbol{F}$.

$6 C, I)$, and with sustained inhibition for the high-level excitatory inputs (Fig. 6E,H).

The effects of phasic inhibition depended on the input frequency. When the input frequency was $>500 \mathrm{~Hz}$, the phasic inhibition reduced the in-phase firing (data not shown). This reduction was due to IPSCs affecting the in-phase firing of the next cycle. In-phase firing was also affected by the time course of the IPSC and was reduced even at $200 \mathrm{~Hz}$ input frequency when the IPSC time course was prolonged to more than twice the length of the present simulation by setting the time constant of the $\alpha$ function to $2 \mathrm{~ms}$. The delay of the IPSC relative to the ipsilateral EPSC was found to be between 1 and $2 \mathrm{~ms}$ (Fig. 1Da), and the in-phase firing was reduced at $333 \mathrm{~Hz}$ when the delay was set to $2 \mathrm{~ms}$. These findings indicate that the time window created by phasic inhibition from local GABAergic neurons could be effective in enhancing the peak-trough contrast, particularly for the low-frequency inputs.
Sustained and phasic inhibition enhanced ITD sensitivity over a wide sound-intensity range

The peak-trough contrast of the ITD-tuning curve was calculated over a wide range of excitatory input levels (Fig. 7, plotted after normalization). We assume here that the excitatory conductance represents the sound intensity and that the conductance of sustained inhibition increased linearly with the excitatory conductance (Nishino et al., 2008); thus, we made the sustained inhibition in proportion to 1-4 times the excitatory conductance. In contrast, we applied a phasic inhibition with a constant conductance (independent of the sound intensity) because the amplitude of the IPSC was relatively insensitive to the stimulus intensity (Fig. $1 E a$ ). The conductance level (90-360 nS; Fig. 7B) of the phasic inhibition was adopted to generate the maximum peak-trough contrasts that were similar to the levels of the sustained inhibition (Fig. 7A).

With sustained inhibition alone, the peak-trough contrast increased with an increase in the inhibitory conductance (1-3 
times; Fig. 7A) particularly at the highlevel excitatory inputs. With the weak sustained inhibition $(\times 1)$, the peak-trough contrast was reduced at high-level excitatory inputs because firing occurred regardless of the ITD. With very high sustained inhibition $(\times 4)$, the firing rate was reduced even for the in-phase ITD, and the peak-trough contrast was reduced for both the low- and high-level excitatory inputs (Fig. 7A, green broken line). With the phasic inhibition alone, the peak-trough contrast increased with increasing inhibitory conductance, but when the excitatory input was low (Fig. $7 B)$. Even when the phasic inhibitory conductance was made proportional to the excitatory conductance as in the case of sustained inhibition, the peak-trough contrast was not different from the present case and was high for the low-level and low for the high-level excitatory inputs (data not shown). Thus, the peak-trough contrast in ITD-tuning is dependent on both the mode of inhibition and the level of excitatory inputs.

When the phasic inhibition (180 nS) was combined with a sustained inhibition (three times the excitatory conductance), the contrast of ITD-tuning curves was maintained at a high level across various levels of excitatory inputs (Fig. 7C,D, open squares). This finding was because the addition of the phasic inhibition further increased the peak-trough contrast, particularly for the low-level excitatory inputs (Fig. 7D, red solid lines; symbols indicate the conductance level of phasic inhibition). Thus, the peak-trough contrast of ITD-tuning could be maintained at high levels in the NL over a wide range of excitatory input levels by the cooperative activities of sustained and phasic inhibitions.

\section{Discussion}

In this study, we found that low-CF NL neurons received a feedforward inhibition through local GABAergic neurons, and this inhibition operated in a phasic manner. The IPSC had a rapid decay time course and a short, fixed delay after the EPSC from ipsilateral NM neurons. This phasic inhibition narrowed the time window for bilateral EPSP summation and enhanced the contrast of ITD-tuning, particularly for weak excitatory inputs. In contrast, the sound-intensity-dependent sustained inhibition from the SON improved the ITD-tuning for loud sounds. By operating in a parallel and complementary manner, the sustained and phasic inhibitions appeared to enhance the ITD sensitivity of low-CF NL neurons over a wide range of sound intensities.

\section{Cooperation of phasic and sustained inhibition in ITD processing of low-frequency sounds}

In vivo single-unit recordings have revealed that low-CF NL neurons are responsive to ITDs over a wide range of sound intensities (Nishino et al., 2008). The present study corroborates this finding with simulations that included phasic and sustained inhibitions
B
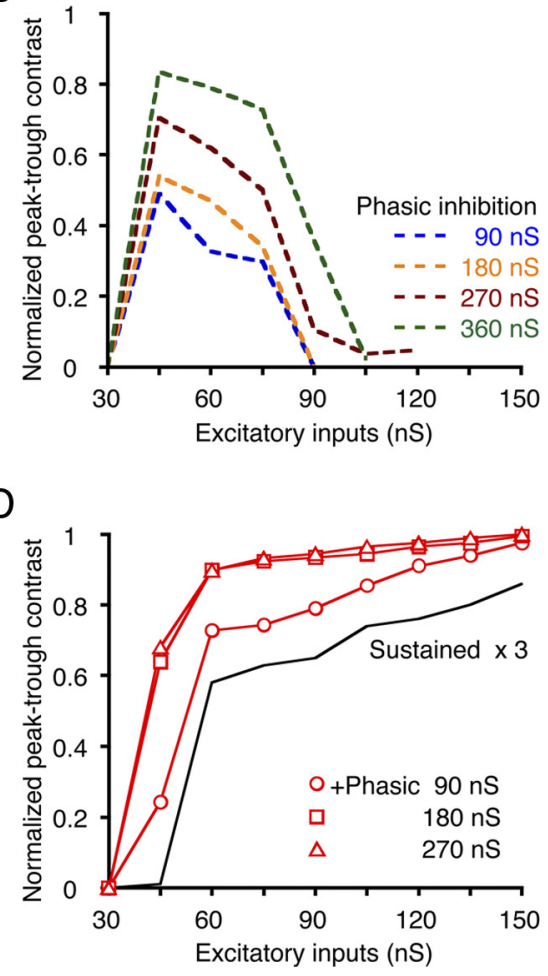

Figure 7. The effects of sustained and phasic inhibition depend on the level of excitatory input and are complementary. $A, B, A$ series of peak-trough contrasts in the ITD-tuning curves was calculated as a function of the excitatory conductance level with

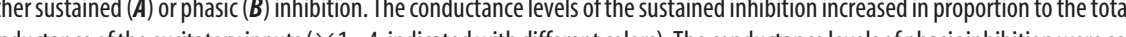
(190 conductance level of the excitatory inputs. $D$, The peak-trough contrasts were lculated by including both the sustained and phasic inhibition. The black line indicates the peak-trough contrast with sustained inhibition adopted from $\boldsymbol{A}$ ( $\times 3$ of excitatory input). The phasic inhibitions of the different conductance levels improved the

(Fig. $7 C, D$ ). In the previous experiments, an electrical lesion of the SON reduced the peak-trough contrast of ITD-tuning in low-CF NL neurons, particularly for loud sounds. However, the contrast for weak to intermediate sound intensities was preserved close to normal levels in several cases (Nishino et al., 2008, their Fig. 5D). We previously interpreted those results as a consequence of different levels of SON injury (Nishino et al., 2008). However, the present results may indicate that the peak-trough contrast was maintained after the SON lesion due to the activity of the phasic inhibition from local GABAergic neurons. For a more definitive understanding of the functional roles of phasic inhibition in ITD processing, we need to develop a novel methodology that can modulate the inhibitory projections from local GABAergic neurons to the NL.

The auditory firing activities are generally highly phase locked for low-frequency sounds; however, there is significant fluctuation in the timing of the spikes in low-frequency ANFs (Hill et al., 1989; Köppl, 1997). While temporal precision is somewhat improved in the transmissions from the ANF to the cochlear nucleus (Joris et al., 1994; Fukui and Ohmori, 2004; Fukui et al., 2006; Kuba and Ohmori, 2009), the lowfrequency NM neurons still retain a large jitter in spike timing (Fukui et al., 2006; 150-400 $\mu$ s at 100-200 Hz). Thus, this dual inhibitory mechanism would be important for the low-CF NL neurons to overcome this disadvantage and process precisely the ITD cues. 


\section{Fast decay kinetics of the IPSC}

Inhibitory transmission in the NA is mediated both by the glycinergic component and GABAergic component, and the IPSCs have a fast decay time course (Kuo et al., 2009). An immunohistological study revealed that glycine labeling was also observed to some extent in the NM and NL (Code and Rubel, 1989; Kuo et al., 2009); however, electrophysiological studies have found a lack of glycinergic synaptic currents in these regions (Funabiki et al., 1998; Kuo et al., 2009). Along with preceding publications (Yamada et al., 2009a,b; Tang and Lu, 2012), this study indicates that IPSC time courses in the NL have a tonotopic gradient with faster time courses in the low-CF neurons (Fig. 5). Tang and $\mathrm{Lu}$ (2012) suggested that the synchronicity of inhibitory transmission might contribute to this gradient. The present study further indicates that the tonotopic differences are also attributable to the differential expression of $\mathrm{GABA}_{\mathrm{A}}$ receptor subtypes (Fig. $5 E, F$ ).

$\mathrm{GABA}_{\mathrm{A}}$ receptors are pentameric hetero-oligomers derived from seven classes of subunits, and their subunit composition strongly affects their decay kinetics (Mody and Pearce, 2004; Farrant and Nusser, 2005). The $\alpha$-subunit family comprises six different subtypes $(\alpha 1-\alpha 6)$ (Fritschy et al., 1997). The receptors that contain the $\alpha 1$-subunit have faster decay kinetics than other receptors (McClellan and Twyman, 1999; Vicini et al., 2001; Goldstein et al., 2002; Eyre et al., 2012). The expression of the $\alpha 1$-subunit is negligible in NM neurons, whereas the expression is extremely high in low-CF NL neurons (Fig. 5). The amplitudes and $10-90 \%$ rise-times of the sIPSCs were similar in the NL neurons in the three CF regions (Fig. 5), suggesting that neurotransmitter release and synaptic receptor localization are similar among neurons of the three CF regions of the NL. Thus, the expression of the $\alpha 1$-subunit in low-CF NL neurons is responsible for the fast decay kinetics of IPSCs.

Even in the low-CF NL neurons, the decay time constant of sIPSCs distributed in a longer range ( $<15 \mathrm{~ms}$; Fig. $5 B)$. This wide distribution of the decay time constants of the sIPSCs might be responsible for the multiple decay time constants of the evoked IPSCs (Fig. 1). Furthermore, decay kinetics of synaptic currents should be affected by the synchronicity of synaptic transmission as demonstrated by Tang and $\mathrm{Lu}$ (2012). The major origin of presynaptic inhibitory neurons is the SON in the low-CF NL neurons (Lachica et al., 1994; Nishino et al., 2008), which might increase asynchronicity of transmitter release and prolong the decay phase of sIPSC. The evoked IPSCs demonstrated a still faster decay kinetics (Table 1) than that of low-CF sIPSCs (Fig. 5), particularly for the faster decay component when fit by double-exponential function, indicating that the monosynaptic innervation from the NM neurons could further optimize the synchronization of transmitter release from the local GABAergic neurons.

\section{Phasic neurons in the SON}

In the NL, SON inhibition is sound-intensity dependent, and it controls the gain of ITD processing (Peña et al., 1996; Nishino et al., 2008). Furthermore, GABA-mediated sustained inhibition has been demonstrated to improve coincidence detection in NL slice preparations (Funabiki et al., 1998; Tang et al., 2011). The SON comprises heterogeneous neurons, most of which fire in a nonphasic manner. However, some neurons respond in a phasic manner to sound stimuli in vivo (Lachica et al., 1994; Coleman et al., 2011). This phasic response of SON neurons may give rise to phasic inhibition in the NL. However, further investigation is required to understand their roles. In particular, the pathway that includes SON phasic neurons may not play a role in sharpening the time window for coincidence detection in the NL due to the large number of synapses included in the long circuits that originate in the ANF. Transmission through the ANF-NASON-NL or the ANF-NM-NL-SON-NL circuits (Lachica et al., 1994) would significantly increase the time of onset and the fluctuation of signals in the NL.

\section{Comparison with ITD coding in mammals}

Mammals are known to use low-frequency sound for ITD coding (Grothe, 2003; Harper and McAlpine, 2004), and inhibitory systems have been proposed to play significant roles in ITD coding. Mammalian MSO neurons receive bilateral glycinergic feedforward inhibitions. These inhibitions are known to have a phaselocked nature (Spirou et al., 1998; von Gersdorff and Borst, 2002) and shape the time window for coincidence detection and spike generation (Grothe and Sanes, 1994). In vivo studies have indicated that phase-locked, feedforward inhibition may create a delay in the rise of EPSPs, which would increase the sensitivity of the MSO neurons within the physiologically relevant range of ITDs (McAlpine et al., 2001; Brand et al., 2002; Grothe, 2003; Pecka et al., 2008). This phase-locked inhibition also reaches to the lateral superior olive, which encodes interaural intensity differences, and its short time course creates the ITD sensitivity observed there (Park et al., 1996). Our present findings show that low-CF NL neurons in birds also receive phasic inhibition; however, this inhibition is from local GABAergic neurons. In NL neurons, we found that phasic inhibition enhanced the contrast of ITDtuning by creating a short time window for coincidence detection, rather than creating an internal delay to compensate for the ITD in the MSO (Brand et al., 2002). Although the role of phasic inhibition in the NL might differ from that proposed in the MSO, our findings suggest that feedforward inhibitory circuits play significant roles in processing the ITDs of low-frequency sounds in both mammals and birds. Moreover, it is important to note that the ITD-tuning of both the NL and MSO neurons is maintained for loud sounds (Peña et al., 1996; Dasika et al., 2005; Nishino et al., 2008; Pecka et al., 2008). The present study reveals complementary functions of phasic and sustained inhibitions in coincidence detection that might facilitate the accurate processing of the spatial auditory cues regardless of input intensity.

\section{References}

Brand A, Behrend O, Marquardt T, McAlpine D, Grothe B (2002) Precise inhibition is essential for microsecond interaural time difference coding. Nature 417:543-547. CrossRef Medline

Burger RM, Cramer KS, Pfeiffer JD, Rubel EW (2005) Avian superior olivary nucleus provides divergent inhibitory input to parallel auditory pathways. J Comp Neurol 481:6-18. CrossRef Medline

Carr CE, Fujita I, Konishi M (1989) Distribution of GABAergic neurons and terminals in the auditory system of the barn owl. J Comp Neurol 286:190207. CrossRef Medline

Code RA, Rubel EW (1989) Glycine-immunoreactivity in the auditory brain stem of the chick. Hear Res 40:167-172. CrossRef Medline

Coleman WL, Fischl MJ, Weimann SR, Burger RM (2011) GABAergic and glycinergic inhibition modulate monaural auditory response properties in the avian superior olivary nucleus. J Neurophysiol 105:2405-2420. CrossRef Medline

Curtis DR, Eccles JC (1960) Synaptic action during and after repetitive stimulation. J Physiol 150:374-398. Medline

Dasika VK, White JA, Carney LH, Colburn HS (2005) Effects of inhibitory feedback in a network model of avian brain stem. J Neurophysiol 94:400414. CrossRef Medline

Eyre MD, Renzi M, Farrant M, Nusser Z (2012) Setting the time course of inhibitory synaptic currents by mixing multiple $\mathrm{GABA}_{\mathrm{A}}$ receptor $\alpha$ subunit isoforms. J Neurosci 32:5853-5867. CrossRef Medline

Farrant M, Nusser Z (2005) Variations on an inhibitory theme: phasic and 
tonic activation of $\mathrm{GABA}_{\mathrm{A}}$ receptors. Nat Rev Neurosci 6:215-229. CrossRef Medline

Fritschy JM, Benke D, Johnson DK, Mohler H, Rudolph U (1997) $\mathrm{GABA}_{\mathrm{A}^{-}}$ receptor $\alpha$-subunit is an essential prerequisite for receptor formation in vivo. Neuroscience 81:1043-1053. CrossRef Medline

Fukui I, Ohmori H (2004) Tonotopic gradient of membrane and synaptic properties for neurons of the chicken nucleus magnocellularis. J Neurosci 24:7514-7523. CrossRef Medline

Fukui I, Sato T, Ohmori H (2006) Improvement of phase information at low sound frequency in nucleus magnocellularis of the chicken. J Neurophysiol 96:633-641. CrossRef Medline

Fukui I, Burger RM, Ohmori H, Rubel EW (2010) GABAergic inhibition sharpens the frequency tuning and enhances phase locking in chicken nucleus magnocellularis neurons. J Neurosci 30:12075-12083. CrossRef Medline

Funabiki K, Koyano K, Ohmori H (1998) The role of GABAergic inputs for coincidence detection in the neurones of nucleus laminaris of the chick. J Physiol 508:851-869. CrossRef Medline

Goldstein PA, Elsen FP, Ying SW, Ferguson C, Homanics GE, Harrison NL (2002) Prolongation of hippocampal miniature inhibitory postsynaptic currents in mice lacking $\mathrm{GABA}_{\mathrm{A}}$ receptor $\alpha 1$ subunit. J Neurophysiol 88:3208-3217. CrossRef Medline

Grothe B (2003) New roles for synaptic inhibition in sound localization. Nat Rev Neurosci 4:540-550. CrossRef Medline

Grothe B, Sanes DH (1994) Synaptic inhibition influences the temporal coding properties of medial superior olivary neurons: an in vitro study. J Neurosci 14:1701-1709. Medline

Harper NS, McAlpine D (2004) Optimal neural population coding of an auditory spatial cue. Nature 430:682-686. CrossRef Medline

Hill KG, Stange G, Mo J (1989) Temporal synchronization in the primary auditory response in the pigeon. Hear Res 39:63-73. CrossRef Medline

Hines ML, Morse T, Migliore M, Carnevale NT, Shepherd GM (2004) Model DB: a database to support computational neuroscience. J Comput Neurosci 17:7-11. CrossRef Medline

Hyson RL, Reyes AD, Rubel EW (1995) A depolarizing inhibitory response to GABA in brainstem auditory neurons of the chick. Brain Res 677:117126. CrossRef Medline

Joris P, Yin TC (2007) A matter of time: internal delays in binaural processing. Trends Neurosci 30:70-78. CrossRef Medline

Joris PX, Carney LH, Smith PH, Yin TC (1994) Enhancement of neural synchronization in the anteroventral cochlear nucleus. I. Responses to tones at the characteristic frequency. J Neurophysiol 71:1022-1036. Medline

Konishi M (2003) Coding of auditory space. Annu Rev Neurosci 26:31-55. CrossRef Medline

Köppl C (1997) Phase locking to high frequencies in the auditory nerve and cochlear nucleus magnocellularis of the barn owl, Tyto alba. J Neurosci 17:3312-3321. Medline

Kuba H, Ohmori H (2009) Roles of axonal sodium channels in precise auditory time coding at nucleus magnocellularis of the chick. J Physiol 587: 87-100. CrossRef Medline

Kuba H, Yamada R, Ohmori H (2003) Evaluation of the limiting acuity of coincidence detection in nucleus laminaris of the chicken. J Physiol 552: 611-620. CrossRef Medline

Kuba H, Yamada R, Fukui I, Ohmori H (2005) Tonotopic specialization of auditory coincidence detection in nucleus laminaris of the chick. J Neurosci 25:1924-1934. CrossRef Medline

Kuba H, Ishii TM, Ohmori H (2006) Axonal site of spike initiation enhances auditory coincidence detection. Nature 444:1069-1072. CrossRef Medline

Kuo SP, Bradley LA, Trussell LO (2009) Heterogeneous kinetics and pharmacology of synaptic inhibition in the chicken auditory brainstem. J Neurosci 29:9625-9634. CrossRef Medline

Lachica EA, Rübsamen R, Rubel EW (1994) GABAergic terminals in nucleus magnocellularis and laminaris originate from the superior olivary nucleus. J Comp Neurol 348:403-418. CrossRef Medline

McAlpine D, Jiang D, Palmer AR (2001) A neural code for low-frequency sound localization in mammals. Nat Neurosci 4:396-401. CrossRef Medline

McClellan AM, Twyman RE (1999) Receptor system response kinetics re- veal functional subtypes of native murine and recombinant human $\mathrm{GABA}_{\mathrm{A}}$ receptors. J Physiol 515:711-727. CrossRef Medline

Mody I, Pearce RA (2004) Diversity of inhibitory neurotransmission through $\mathrm{GABA}_{\mathrm{A}}$ receptors. Trends Neurosci 27:569-575. CrossRef Medline

Nishino E, Yamada R, Kuba H, Hioki H, Furuta T, Kaneko T, Ohmori H (2008) Sound-intensity-dependent compensation for the small interaural time difference cue for sound source localization. J Neurosci 28:7153-7164. CrossRef Medline

Park TJ, Grothe B, Pollak GD, Schuller G, Koch U (1996) Neural delays shape selectivity to interaural intensity differences in the lateral superior olive. J Neurosci 16:6554-6566. Medline

Pecka M, Brand A, Behrend O, Grothe B (2008) Interaural time difference processing in the mammalian medial superior olive: the role of glycinergic inhibition. J Neurosci 28:6914-6925. CrossRef Medline

Peña JL, Viete S, Albeck Y, Konishi M (1996) Tolerance to sound intensity of binaural coincidence detection in the nucleus laminaris of the owl. J Neurosci 16:7046-7054. Medline

Rathouz M, Trussell L (1998) Characterization of outward currents in neurons of the avian nucleus magnocellularis. J Neurophysiol 80:2824-2835. Medline

Rayleigh L (1907) On our perception of sound direction. Phil Mag 13:214-232.

Renshaw B (1940) Activity in the simplest spinal reflex pathways. J Neurophysiol 3:373-387.

Rothman JS, Manis PB (2003) The roles potassium currents play in regulating the electrical activity of ventral cochlear nucleus neurons. J Neurophysiol 89:3097-3113. CrossRef Medline

Rubel EW, Parks TN (1975) Organization and development of brain stem auditory nuclei of the chicken: tonotopic organization of n. magnocellularis and n. laminaris. J Comp Neurol 164:411-433. CrossRef Medline

Simon JZ, Carr CE, Shamma SA (1999) A dendritic model of coincidence detection in avian brainstem. Neurocomputing 26-27:263-269.

Spirou GA, Rowland KC, Berrebi AS (1998) Ultrastructure of neurons and large synaptic terminals in the lateral nucleus of the trapezoid body of the cat. J Comp Neurol 398:257-272. CrossRef Medline

Tabor KM, Coleman WL, Rubel EW, Burger RM (2012) Tonotopic organization of the superior olivary nucleus in the chicken auditory brainstem. J Comp Neurol 520:1493-1508. CrossRef Medline

Tang ZQ, Lu Y (2012) Two GABA $A_{A}$ responses with distinct kinetics in a sound localization circuit. J Physiol 590:3787-3805. CrossRef Medline

Tang ZQ, Hoang Dinh EH, Shi W, Lu Y (2011) Ambient GABA-activated tonic inhibition sharpens auditory coincidence detection via depolarizing shunting mechanism. J Neurosci 31:6121-6131. CrossRef Medline

Vicini S, Ferguson C, Prybylowski K, Kralic J, Morrow AL, Homanics GE (2001) $\mathrm{GABA}_{\mathrm{A}}$ receptor $\alpha 1$ subunit deletion prevents developmental changes of inhibitory synaptic currents in cerebellar neurons. J Neurosci 21:3009-3016. Medline

von Bartheld CS, Code RA, Rubel EW (1989) GABAergic neurons in brainstem auditory nuclei of the chick: distribution, morphology, and connectivity. J Comp Neurol 287:470-483. CrossRef Medline

von Gersdorff H, Borst JG (2002) Short-term plasticity at the calyx of Held. Nat Rev Neurosci 3:53-64. CrossRef Medline

Warchol ME, Dallos P (1990) Neural coding in the chick cochlear nucleus. J Comp Physiol A 166:721-734. Medline

Yamada R, Kuba H, Ishii TM, Ohmori H (2005) Hyperpolarization-activated cyclic nucleotide-gated cation channels regulate auditory coincidence detection in nucleus laminaris of the chick. J Neurosci 25:8867-8877. CrossRef Medline

Yamada R, Okuda H, Nishino E, Kuba H, Ishii TM, Ohmori H (2009a) Roles of phase-locked inhibition for processing interaural time difference cue in the nucleus laminaris of birds. 36th Inter Congr Physiol Sci Abstr. Proceedings of IUPS 2009 (P1PM-10-6), J Physiol Sci 59 [Suppl. 1]:188.

Yamada R, Okuda H, Nishino E, Kuba H, Ishii TM, Ohmori H (2009b) Precisely timed inhibition for processing interaural time difference cue at low frequency in the nucleus laminaris of birds. Soc Neurosci Abstr 35:259.5.

Yang L, Monsivais P, Rubel EW (1999) The superior olivary nucleus and its influence on nucleus laminaris: a source of inhibitory feedback for coincidence detection in the avian auditory brainstem. J Neurosci 19:23132325. Medline 